\title{
Industrial Heritage Valorisation and Creative Industry Proliferation in Shanghai's Urban Regeneration
}

\author{
Yi-Wen Wang ${ }^{\text {a* }}$ and Xiangyi Wang ${ }^{b}$ \\ a Department of Urban Planning and Design, Xi'an Jiaotong-Liverpool University, Suzhou, China \\ $b$ Urban Space Planning and Architectural Design Co., LTD (Shenzhen) Shanghai Branch, Shanghai, China \\ * Corresponding author: yiwen.wang@xjtlu.edu.cn
}

\begin{abstract}
While industrial manufacturing is giving way to the creative economy in the $21^{\text {st }}$ century, Shanghaisimilar to many major cities around the world-is keen to bolster a stronger economy and increase its competitiveness by encouraging the development of cultural and creative industries. Over the past decade, the Shanghai municipal government has made a concerted effort to exploit the heritage assets of the city's industrial past to reform its economic structure. There has been a deliberate attempt to establish a stronger correlation between industrial heritage conservation and creative industry cluster development. The aim of this research is to investigate the process of converting former industrial sites into loci of creativity. In doing so, we can determine the main actors, how different stakeholder groups came into play and the evolution of the subtle interplay between the designation of heritage architecture and that of creative industry cluster. Drawing on qualitative research methods, this paper presents a detailed analysis of three case studies in Shanghai: M50 Creative Park, 1933 Shanghai and the Cool Docks. The results reveal the changing positions of three major stakeholder groups. Whereas the private sector and the general public have developed increasing interests in the embedded economic and cultural values of the former industrial structures, local government has consciously reduced its presence and influence in valorising industrial heritage. Thus, the growing public awareness of cultural heritage protection and the increasing interest in the economic contribution of cultural and creative industries are intrinsic to Shanghai's reindustrialisation in the $21^{\text {st }}$ century.
\end{abstract}

KEYWORDS industrial heritage, creative industry, urban governance, stakeholder, Shanghai

Received April 16, 2018; accepted June 16, 2018.

\section{Introduction}

Cities have been acknowledged for their productive role in nurturing culture and creativity and are considered breeding grounds for imaginative ideas, innovative designs and revolutionary vanguards. However, while the knowledgebased economy came to prominence at the turn of the $21^{\text {st }}$ century, a new form of urbanism and local governance has emerged. This new school of thought has increasingly seen cultural and creative industries as preconditions for enhancing the social liveability and economic competitiveness of cities (Wu 2000; Florida 2005; Landry 2008; Kong and O'Connor 2009; He 2014).

In Shanghai, such a phenomenon is particularly evident in the reuse of $20^{\text {th }}$-century industrial heritage buildings. Over the past decade, there has been a series of demands for rethinking or, more controversially, exploiting the heritage assets of the city's industrial past in a shift away from manufacturing to the service industry and to achieve growth in a knowledge-based economy. There have been deliberate efforts to establish a stronger correlation between industrial heritage conservation and creative industry cluster designation. Obsolete manufacturing plants and sites were successively reinvented and turned into a breeding ground for creative industry and innovative enterprise. This close relationship is abundantly evident in the existing body of literature on the Shanghai municipal government's initiative to develop 'Creative Industry Clusters' (CICs) and its entrepreneurial endeavours and attempts behind this initiative. Extensive research has been carried out on the application and effectiveness of CICs as a new planning instrument to boost the knowledge-based economy of the city (O'Connor 2009; 
Table 1 Background information of the selected three study cases (Source: Xiangyi Wang).

\begin{tabular}{|l|l|l|l|}
\hline & \multicolumn{1}{|c|}{ M50 } & \multicolumn{1}{|c|}{ 1933 Shanghai } & \multicolumn{1}{c|}{ The Cool Docks } \\
\hline Construction Year & 1930s & 1933 & $1900 \mathrm{~s}-1930 \mathrm{~s}$ \\
\hline Regeneration Year & 2004 & 2006 & 2007 \\
\hline Original Use & Textile Factories & Slaughterhouse & Grease Factories and Warehouses \\
\hline Location & $\begin{array}{l}50, \text { Moganshan Road, } \\
\text { Putuo District }\end{array}$ & $\begin{array}{l}10 \text { and 29, Shajin Road, } \\
\text { Hongkou District }\end{array}$ & $\begin{array}{l}\text { 505, ZhongShan Southern Road, } \\
\text { Huangpu District }\end{array}$ \\
\hline
\end{tabular}

Tung 2009; Zheng 2010; Zhong 2010; Zheng 2011; Gu 2012; O'Connor and Gu 2012; Luan, Wang, and An 2013; He 2014). On the other hand, several studies have focused on the rehabilitation of former industrial structures, questioning the delicate balance between heritage protection and economic development and addressing the conservation issues arising from functional conversion or physical alteration (Ruan and Zhang 2004; Zhang 2007; Ma 2009; Ju, Mei, and Fei 2010). While numerous studies have focused on either the development of CICs or the conservation of industrial sites in Shanghai, few have investigated the transformation process of disused industrial sites into CICs and the key actors and mechanisms that facilitate such transformations.

This research, therefore, examines the process of converting former industrial sites into loci of creativity to determine the key actors, how different stakeholder groups came into play, and to reveal subtle interplay between the designation of heritage architecture and that of CICs. To address the above aims, the methodological approaches adopted in this research follow a case-study design, and include in-depth interviews with key actors who have participated in or possess insider information about the transformation process. Given the exploratory nature of the research, three case studies are examined: M50 Creative Park, 1933 Shanghai and the Cool Docks (Table 1, Figure 1). While all three examples were built in the early $20^{\text {th }}$ century, they are located in different districts and represent different types of manufacturing industries. The regeneration projects of the three cases were undertaken at around the same time, but only one case-1933 Shanghai-has received official recognition for its heritage value from the municipal government, that is, 'Heritage Architecture' status. All the three sites have been designated as a CIC, but at different points in time during their transformations. While all received support from the Shanghai municipal government to convert the disused industrial site into an accredited base for creative industries, the levels and types of support they received varied a great deal. Thus, these three cases were selected because they share some common features but are different in other subtle aspects, thereby allowing a meaningful comparison among them.

Empirical data were collected by conducting in-depth interviews in April 2013 with one interviewee from each of the three cases; interviews were also held in July 2015 with an official from the Shanghai Creative Industry Centre (SCIC, the government agency promoting and regulating creative industries) and a manager from the Shanghai Creative Industry Investment Cooperation Limited (SCII, a government-own investment entity). The managers of the three sites were working for the property management company managing the CIC at the time of the interview. With the purpose of obtaining preliminary information about the process of regeneration from key actors, interviews were carried out in a semi-structured format with a list of pre-planned questions. Initially, the target interviewees were those from the investment company that had participated in the regeneration project. However, based on the literature review, it was discovered that in the case of M50 and the Cool Docks, these key figures were being transferred to an associated property management company set up by the investment company to operate the business of the CIC. In the case of 1933 Shanghai, the investor (SCIC, a subsidiary to the municipal government but commercially operated) only provided financial support to initiate the regeneration project and had little involvement in the process. Therefore, the property management company could provide more valuable information about the subsequent development and business operations of the case. Thus, the three interviewees were all employed by the property management company in charge of the CIC site. Admittedly, the three interviewees represent a small sample, and it may not be possible 


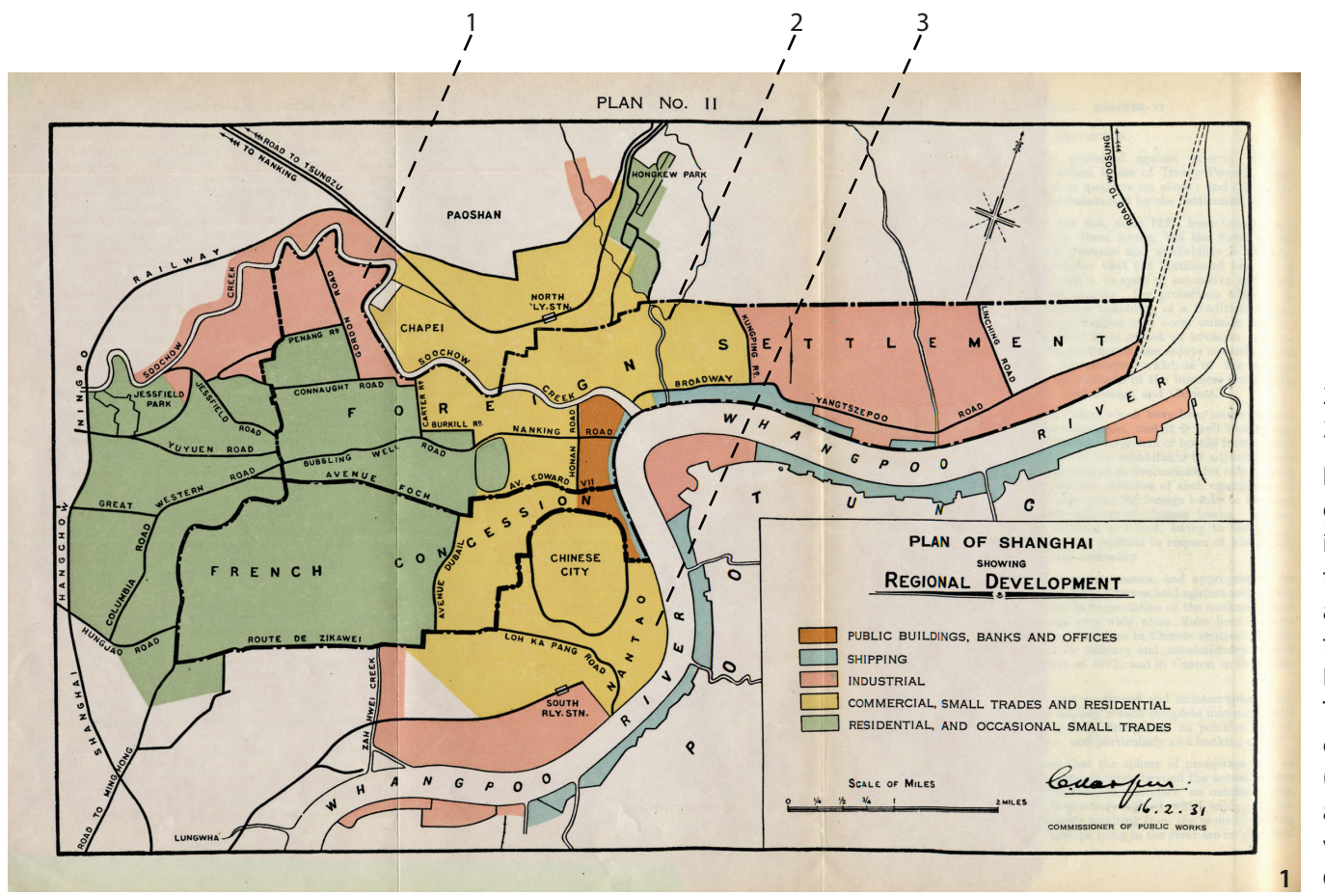

1. $M 50$

2. 1933 Shanghai

3. The Cool Docks

Figure 1 Shanghai Regional Development Plan issued in 1931, showing the industrial and shipping areas being located along the banks of Huangpu River and Suzhou Creek. The location of the three case studies are also noted (Source: Virtual Shanghai, available at http://www. virtualshanghai.net/Maps/ Collection?ID=404).

to generalise the results from this research to all CICs established on a former industrial site. Findings from these interviews, however, enable us to gain an overview of the relationship between CICs and industrial heritage as well as a better understanding of the actual process of transforming a manufacturing site into one for creativity. Additional interviews were conducted with the SCIC official and SCII manager with the purpose of gleaning a greater insight into the nature of these two organisations, the scope of their business operation in aid of the municipal government as well as their involvement in setting up the flagship CIC, 1933 Shanghai.

\section{The Rise, Fall and Transformation of Shanghai's Industrial Production Sites}

Adjacent to the mouth of Yangtze River, Shanghai flourished and became an important costal port in the late $17^{\text {th }}$ century. The city grew quickly and developed into a cosmopolitan city on account of its geographical location and water transport, harbouring both domestic and international trading activities. Its two major waterways, Huangpu River and Suzhou Creek, played an important role in its economic growth, transporting goods from the south to the north, from China to abroad, and vice versa. Following the imposition of a series of unequal treaties with Western powers, international trade in Shanghai increased exponentially in the mid- $19^{\text {th }}$ century. The boom in commodity trading was accompanied by the rise of shipping and the shipbuilding industries, the importation of manufacturing technologies and a large injection of investment capital. At the turn of the $20^{\text {th }}$ century, investment in the manufacturing industry soared high, not only from foreign industrialists but also Chinese manufacturers (Denison and Ren 2006; Zhong 2010). Many factories were erected along the riverbanks in the outskirts of Shanghai (Figure 1) where land was cheap; these areas also provided a free water supply, sewage discharge system and an extensive transport network. In the 1930s, factories in Shanghai accounted for more than $50 \%$ of the national total, and the number of industrial plants in the city rose to more than 10,000 by 1949 (Zhang 2007): 'Despite having no natural resources itself, Shanghai became China's primary industry city, congesting Hongkou's cheap outer districts, Pudong and, later, the banks of Suzhou Creek, all of which combined to form Shanghai's industrial heartland' (Denison and Ren 2006, 119).

From the 1950s to the 1970s, while the new communist government campaigned for agricultural collectivisation and socialist industrialisation to transform the country into a communist society, much of the new government's attention and support for industrial development was redirected toward central and western China (Friedmann 2005). The shift of the industrial development centre from coastal regions to inland provinces did not disrupt Shanghai's industrial production. Instead, the city remained one of the largest industrial centres in the country because 
traditional light manufacturing industries continued to operate there. It was not until the 1980s, and after three decades of socialist industrialisation, that these light industry establishments began to suffer from decline as a result of the long absence of industrial development in coastal areas. The low productivity of old equipment, outdated facilities and, subsequently, diminishing competitiveness all contributed to the decay of Shanghai's manufacturing industry. It is, however, arguable that economic and institutional reforms are the sole factors behind the decline (Zhong 2010).

Following the introduction of economic reform in 1978 (the restructuring of state-owned enterprises), urban land reform and an increasing emphasis on tertiary industry development in coastal cities, industrial firms moved (or subcontracted their production) to suburban areas, rural townships and satellite cities (Friedmann 2005, Zhong 2010). Consequently, a large amount of industrial land and space was left vacant in inner city areas. Under the Eighth Five-Year Plan, and by means of urban land reform, more than 700 old industrial sites were assigned a new function in the land use plan in the early 1990s; such uses included financial, commercial, residential and office areas. The companies that possessed and managed these industrial properties were derived from state-owned enterprises from pre-reform years, and they remained closely associated with central or municipal government. For those with centrally located properties, running new businesses or simply selling the land was a much more profitable undertaking than manufacturing. While many old industrial sites in close proximity to the city centre were sold and converted into other uses, other underutilised areas were leased to artists or small start-up companies that demanded a large studio or office space at a central location with an affordable rent. In the meanwhile, many other industrial sites and factory buildings located in the outer areas were left abandoned once production ceased or was relocated. As the $21^{\text {st }}$ century dawned, these former industrial lands ignored in the 1990s urban renewal were later turned into incubation sites for innovative enterprise; that is, CICs (Zheng 2010; Zhong 2010).

\section{A New Planning Instrument: 'Creative Industry Cluster' Designation}

By the late 1990s, Shanghai had begun to witness the emergence of a high concentration of culture and designrelated businesses - that is, the rise of cultural and creative industries. The demand of artists and small start-up companies for affordable rental spaces in the city led to the spontaneous formation of small clusters of art studios, design firms, media companies, fashion and publishing houses, tourism industries and the like in derelict industrial sites. The spacious rooms, high ceilings and distinctive architectural characteristics of old factory buildings appealed to the individuals and companies engaged in various forms of the industrial reproduction of culture or the production of creativity and innovation. Zheng (2010, 147) notes that early tenants of such industrial spaces included artists, start-up companies and university incubation centres, all of which, in a sense, can be considered as the social actors who shaped the early CICs. Although the primary motivation of these three groups in utilising disused industrial spaces was purely practical and pragmatic, they all represent a bottom-up approach to regenerating urban brownfield sites, successfully restoring vitality to these areas. In contrast to this grass-roots movement, however, the government did not seem to place a high priority on the regeneration of derelict industrial sites during this period (Zhong 2009; Zheng 2010).

It was not until the mid-2000s that the spontaneous growth of clusters and the subsequent financial gains from the clustering effect caught the attention of the municipal government. In 2004, the Shanghai Municipal Economic Commission designated 18 sites as CICs, most of which had already an assemblage of cultural and creative businesses on site. Policies and regulations were also issued accordingly to more effectively promote the development of creative industries. In the following year, the municipal government designated another $18 \mathrm{CICs}$ and set up the SCIC, affiliated to the Economic Commission, to govern practices of creative industries and regulate the market. In 2006, the government went on to designate another two batches. By the end of the year, there were 77 CICs officially accredited by and receiving financial support from the municipal government. These municipal CICs are mainly located along the Huangpu River, Suzhou Creek and Yan'an Elevated Road (Figure 2) (Zhang and Chen 2010; Shanghai Municipal Administration of Culture 2012; Luan, Wang, and An 2013). In parallel with the municipal designation, some subsidiary government bodies-including the District Government and the Street Office-and private organisations also followed the trend, designating or simply renaming some places as a CIC for branding purposes. By 2010, there were more than 300 commercial precincts featuring cultural and creative industries, including those designated by the municipal government (Shanghai Municipal Administration of Culture 2012). 


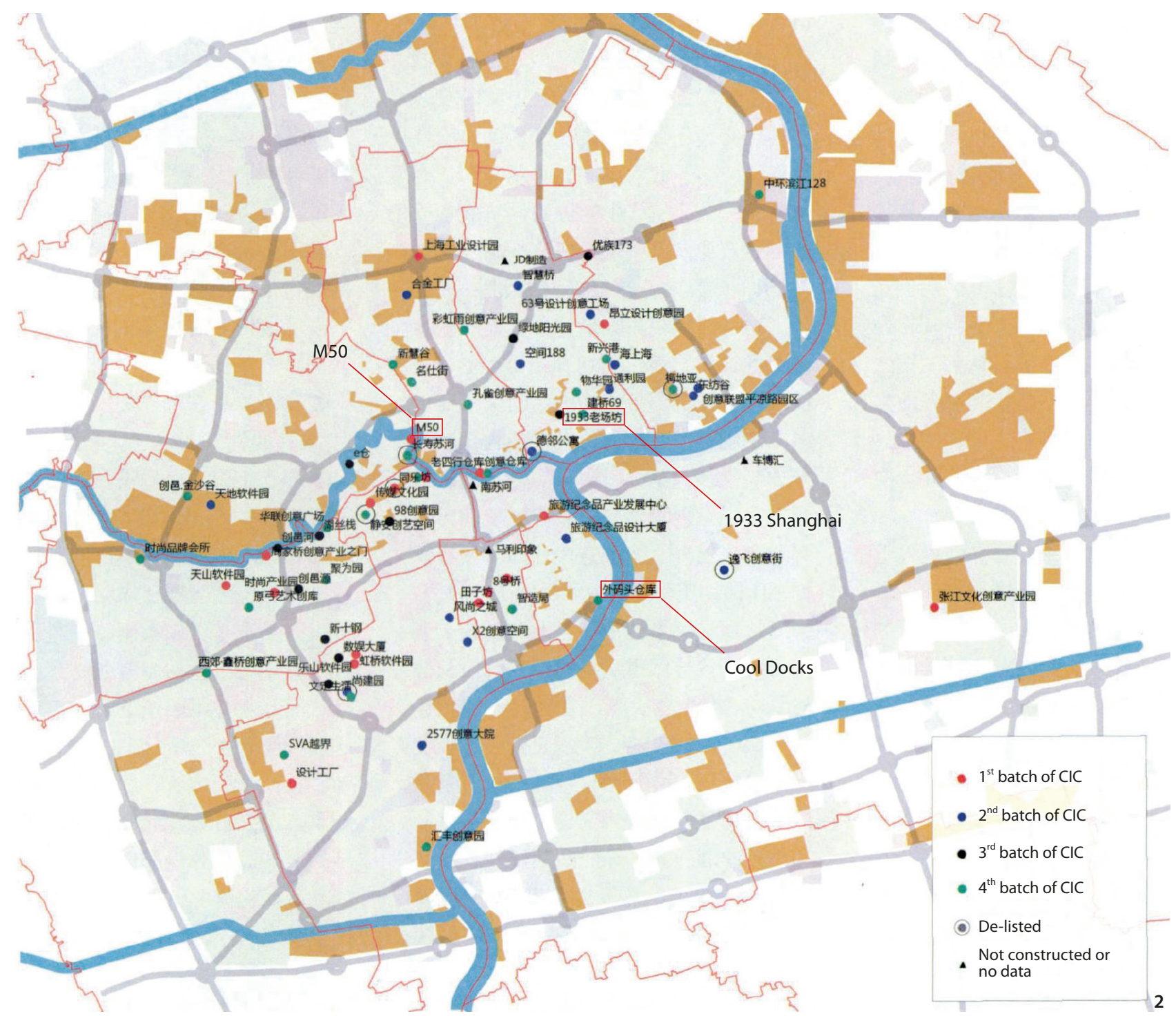

Figure 2 The map of first four batches of CIC designation with 3 study cases highlighted (Source: Luan, Wang, and An 2013).

It can be argued that the rise of creative industries not only led to the variolisation of urban heritage, but it also changed the trajectory of urban governance in Shanghai. Evident in the designation of municipal CICs is that historical buildings were considered an important resource for place promotion. 66 percent of the municipal CICs (57 of 75) were converted from old buildings, most of which were previously for industrial use, though some were once residential and commercial structures (Zhang and Chen 2010; Shanghai Municipal Administration of Culture 2012). The municipal government changed its attitude, gradually yet considerably, toward Shanghai's historical urban fabric. In some cases, the government even scrapped existing redevelopment plans for some former industrial sites after they were designated as CICs, and devised new plans so to retain the historical fabric (Zheng
2011). Nonetheless, Zheng $(2011,3568)$ argues that, while the government became more sympathetic to historical structures, the CICs from 'the second round of designations onward were developed by private developers or public-private coalitions. The commercial characteristics of [CICs] are clear'.

\section{Industrial Heritage: Where Culture Meets Creativity}

Over the past three decades or so, the attitude of the municipal government toward the historical urban fabric has changed markedly. Contrary to the sweeping redevelopment that was commonplace in the 1990s, the local government in the following decade began to dispense with the redevelopment plans of some historical quarters upon being designated as CICs (Zheng 2011). While the low 


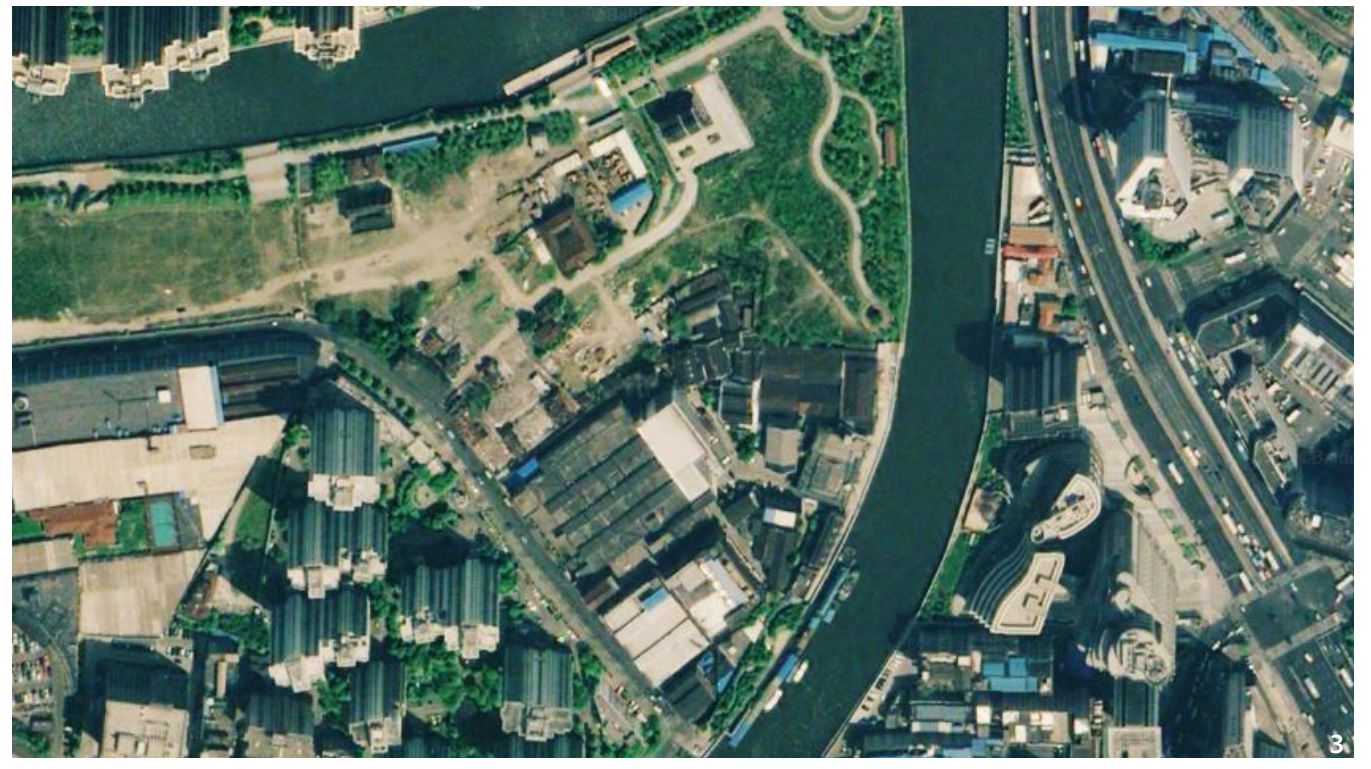

Figure 3 Satellite image of M50 (Source: Baidu Map). effectiveness of CICs in promoting the growth of creative industries in Shanghai has been criticised by some scholars (Zhong 2010; Zheng 2011, He 2014), its effectiveness in recycling and saving industrial buildings and sites has been readily discernible. Not only have more buildings become legally protected, many non-listed industrial buildings have also been retained for their embedded cultural/economic values even though they are not officially listed as Heritage Architecture.

There are various plausible reasons why industrial buildings are preferable subjects for Shanghai's reindustrialisation, but they can be generalised into three major factors: central location, physical features of industrial buildings and their symbolic meanings. Needless to say, a central location is important as it implies a geographical and social proximity to the urban amenities that companies need including transport networks and civil services and facilities. The old industrial structures often have spacious rooms and larger floor areas, which were part of the commercial character sought by CICs. Conservation treatments and conversion approaches applied to old industrial structures can also be classified into three types: retention of the old, addition of the new and the juxtaposition of both, suggesting a connection of the past to the future. The charm of historical buildings is derived from their patina of age, connecting the past with the present and future. It is not just about reusing old structures, but also about the way in which a particular type of aesthetic appreciation is generated by the juxtaposition of the old and the new, suggesting the passage of time. Converting industrial structures into spaces for creative industry workers has stimulated a new wave of architectural aesthetics that appreciates historical industrial character. This includes a wide range of industrial components or details, and has led to the emergence of a new design style in Shanghai (Zheng 2010). The state ownership of these former industrial properties also makes industrial buildings desirable. According to local legislation, 'three unchanging principles', that is, ownership of land use right, the major structure of the building and nature of land use, should be complied with (Wang 2009). To observe this local regulation, the regenerating of former industrial sites with cultural and creative industries has become not only largely feasible but also desirable for those 'new' industries replacing manufacturing.

\section{Case Studies}

Drawing on qualitative research methods, this section gives a detailed analysis of the three selected case studies in Shanghai: M50 Creative Park, 1933 Shanghai and the Cool Docks. To explore these cases in a comparable and consistent manner, and to succinctly delineate their regeneration process, the narratives of the three cases are presented in a chronological manner.

\section{M50}

Located on the banks of Suzhou Creek, M50 is a prime example of the 1930s manufacturing plants established in the golden years of Shanghai. It is also arguably the very first place where creative workers clustered in the 1990s, thereby popularising the idea of CICs in the city (Figure 3 ). The transformation of M50 from a manufacturing site to a home for creative industries provided a reference point for 


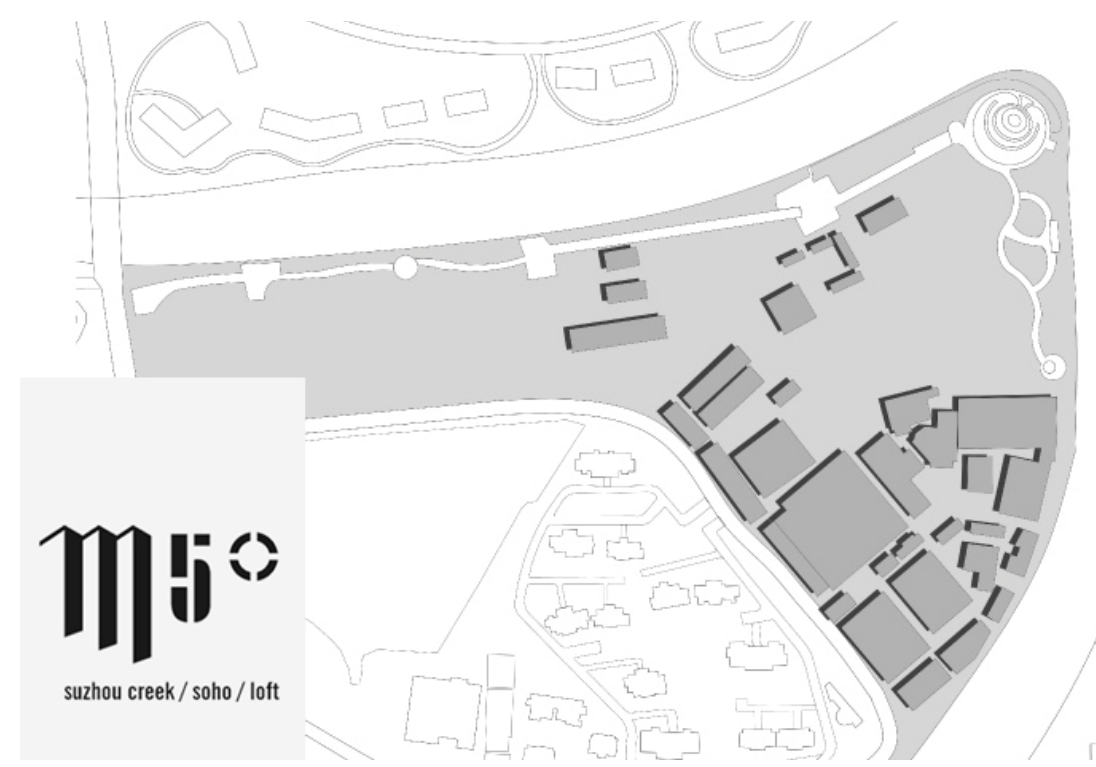

Figure 4 Site plan of M50 (Source: Xiangyi Wang).

Figure 5 The 1930s industrial structures in M50. (Source: Yi-Wen Wang).

Figure 6 Street art and refurbished industrial 4 buildings in M50 (Source: Yi-Wen Wang).
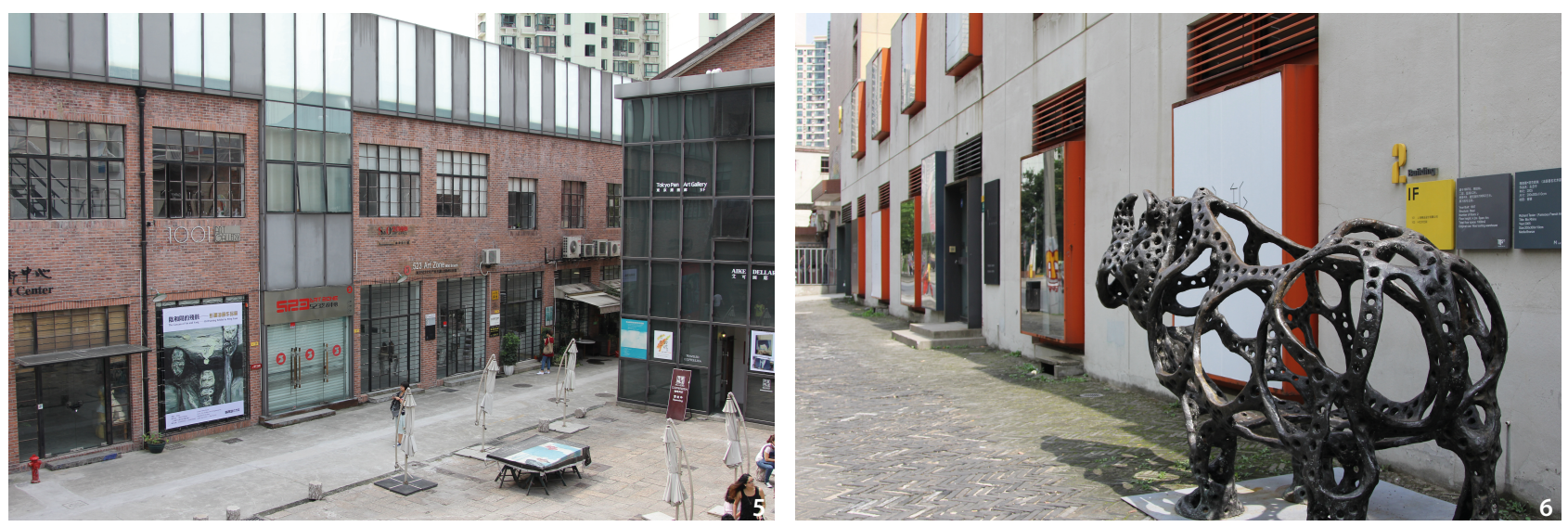

the municipal government to formulate its policy to promote the development of the creative economy as well as CICs in Shanghai (Zhong 2009; 2010).

M50 was originally built for textile production and similar to other factories in the area, the rationale of its siting had most to do with the availability of water resources as well as transport. The area then suffered a decline because of a change to mass production methods. By the end of the 1980s, most industrial establishments in the area had moved out or stopped operating. In 1996, a rehabilitation project for Suzhou Creek was initiated by the local government and this significantly improved the environment as well as the livability and desirability of the area. Following this, artists and designers rediscovered a large stretch of industrial land with many abandoned factories along the river and began to move into the area. This move was first prompted by a Taiwanese architect named Deng Kun Yan, who found a warehouse and turned it into private art studio in 1998. In the coming years, many artists followed Deng, converting former factories and warehouses into their workshops or studios (He 2014). This trend signifies the embryonic form of a 'creative industry cluster' (Figure 4-6). In 2002, this area was listed as an 'Urban Industry Park' by local government and 3 years later, the factory owner renamed this park 'Art Park'. The area was designated as a municipal CIC in 2005 and the owner began to repair and refurbish the old factories and office buildings, with the work being completed the following year. The physical alterations made to existing historical buildings were rather minor and sympathetic. Most of renovations carried out on site were for repairs to the building structure, the refurbishment of surface materials (e.g., plastering, painting or flooring) and the replacement of building details (e.g., doors, windows and fixtures and fittings). Minimal contemporary design features were introduced to the existing buildings, not because these buildings were of heritage value and physical alterations were restricted, but because the area already had many tenants residing on site and the demand for studio space continued to rise. The area was named an 'Outstanding CIC' in 2007 by the 


\begin{tabular}{|c|c|c|c|}
\hline Artists & Government & Investor & Tenants \\
\hline $\begin{array}{l}\text { Leased the } \\
\text { abandoned textile } \\
\text { factories for studio } \\
\text { and working space. }\end{array}$ & $\begin{array}{l}\text { Provided policy } \\
\text { support for } \\
\text { industrial building } \\
\text { reuse. }\end{array}$ & $\begin{array}{l}\text { Designed and built } \\
\text { the brand. }\end{array}$ & $\begin{array}{c}\text { More artists and art } \\
\text { dealers moved into } \\
\text { the side after the } \\
\text { M50 brand became } \\
\text { well known. }\end{array}$ \\
\hline
\end{tabular}

Figure 7 The role that different sectors play in the transformation process of M50 (Source: Xiangyi Wang). municipal government and then renamed in 2008 for branding purpose; since then it has been known as 'M50'. Today, M50 is recognised as the largest cluster of artists and galleries in Shanghai (Wang 2009; Wang 2013).

The development of M50 mostly resulted from the interest of artists to reuse the derelict industrial structures and sites. According to the manager of M50, as a stateowned property, the area was originally designated to be redeveloped for use in the electrical and high technology industries. This plan was then shelved because of objections based on environmental protection grounds (Zheng 2011). Meanwhile, following the residency of an established contemporary artist, the area begun to experience an influx of artists: 'After Xue Song moved into M50, other artists also showed their interest in warehouses, especially as they were about to be demolished' the manager explained, and 'at that time, the owners of original factories started encouraging artists and galleries move into these area'.

While the colonisation of artists in the area may have physically saved the buildings and structures representative of Shanghai's industrial history, the most decisive factor that creatively altered the fate of the area was the property development of surrounding areas between 2001 and 2002. The manager of M50 revealed that 'although this area had already attracted numerous artists, the first development choice [of the property owner, i.e., a stateowned enterprise] is to sell the area to property developers. However, they [the developers] were not satisfied with the high selling price' offered by the local government. Rumour that the owner had made an offer to developers and that the area was under threat of redevelopment soon stirred up widespread agitation and also caught the attention of artists and heritage conservation groups. Led by Professor Ruan Yisan from Tongji University, Shanghai, a group of academics and practitioners surveyed the area and presented to the local government an alternative plan to regenerate the area with the retention of most of the existing structures (Wang 2009). The plan, known in China as 'culture-led regeneration', was accepted and officially approved by the local government. From then on, the conversion of the vast track of industrial land and former derelict textile plants into property for use by creative industries was consolidated. Overtime, M50 has become a fashionable area for both artists and hipsters: 'We already started building our own brand of creative industry rather than the landlords' and 'will never slacken our pace' exclaimed the manager (Figure 7).

\section{Shanghai}

In contrast to the M50 CIC, which was formed organically from the bottom-up by artists, the regeneration process of 1933 Shanghai (Figure 8) represents a top-down approach. Thus, considerable support was obtained from local government to transform the industrial site, which once accommodated a slaughterhouse, into a flagship project for the CIC policy. This later became a catalyst for the regeneration of the area known as the Shanghai Music Valley (González Martínez 2017).

The industrial premises where 1933 Shanghai is located was originally known as the Shanghai Municipal Abattoir, built by the Shanghai Municipal Council (SMC), the governing body of the International Settlement, established by the British. The premises feature an elaborately designed slaughterhouse-a four-storey concrete structure with an intricate vertical and horizontal circulation system to separate humans and cattle and also live animals and hanging carcasses (He and Zhu 2012; Wang and Pendlebury 2016; Pendlebury, Wang, and Law 2018). Designed by a group of British architects in the Public Work Department of the SMC, the building integrated and embodied the principles of modern slaughterhouse design that had been developed since the late $19^{\text {th }}$ century. It is claimed that the building was the largest slaughterhouse in East Asia at the time (He 2011). Equipped with state-of-the-art technology for animal slaughtering in the 1930 s, this modern slaughterhouse was gradually rendered obsolete, and its food production ceased in 1970. The former slaughterhouse building was then converted into a pharmaceutical factory and then a warehouse in the following three decades; by 2002 it was empty. The derelict building soon attracted the attention and concern of an activist and author (also a 

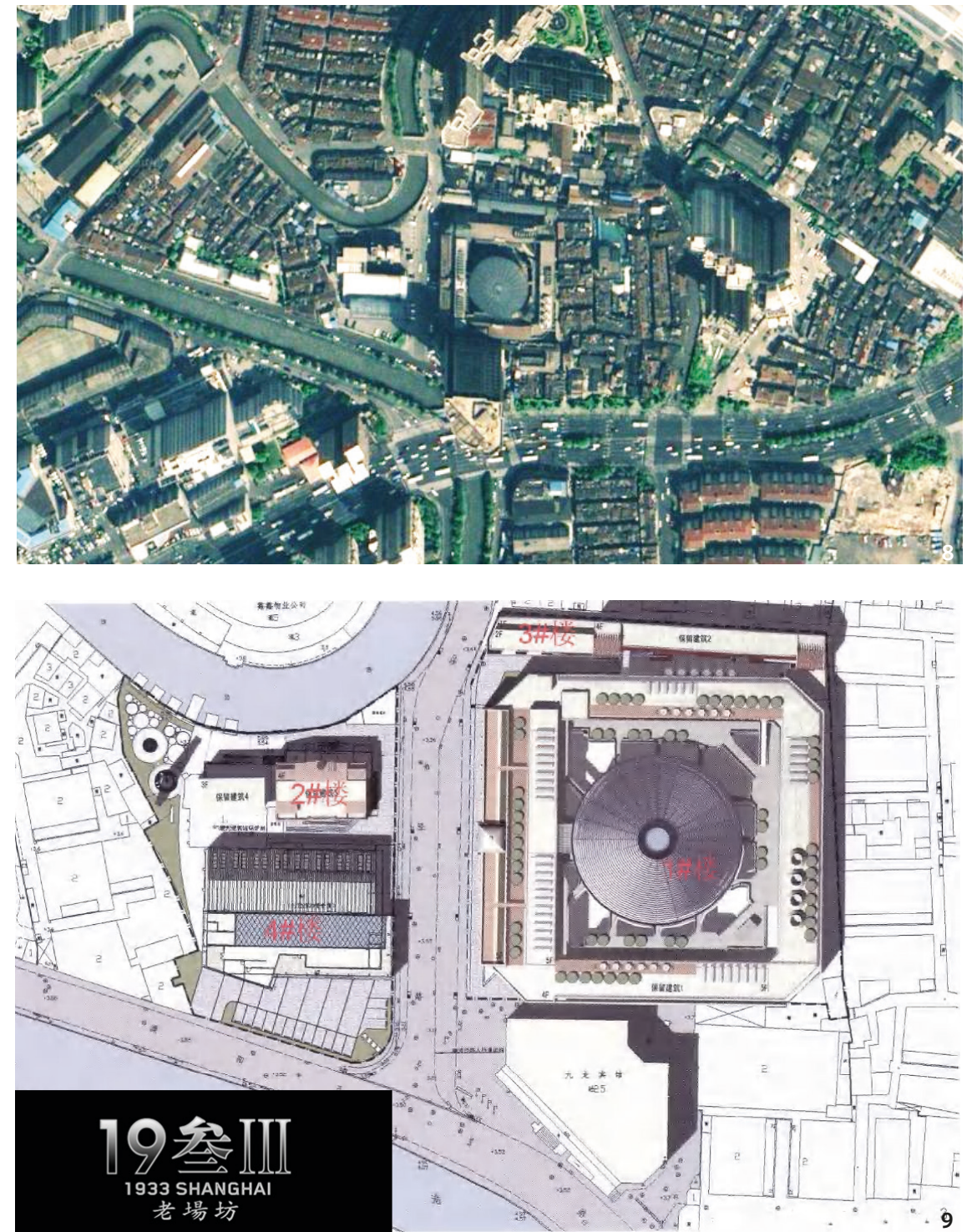

Figure 8 Satellite image of 1933 (Source: Baidu Map).

Figure 9 Site plan of 1933 (Source: Zhao 2007).

Figure 10 The restored façade of 1933 Building (Source: Yi-Wen Wang).

Figure 11 Retails and shops in 1933 Building after conversion (Source: Yi-Wen Wang). Figure 12 The transformation process of 1933 Shanghai (Source: Xiangyi Wang).
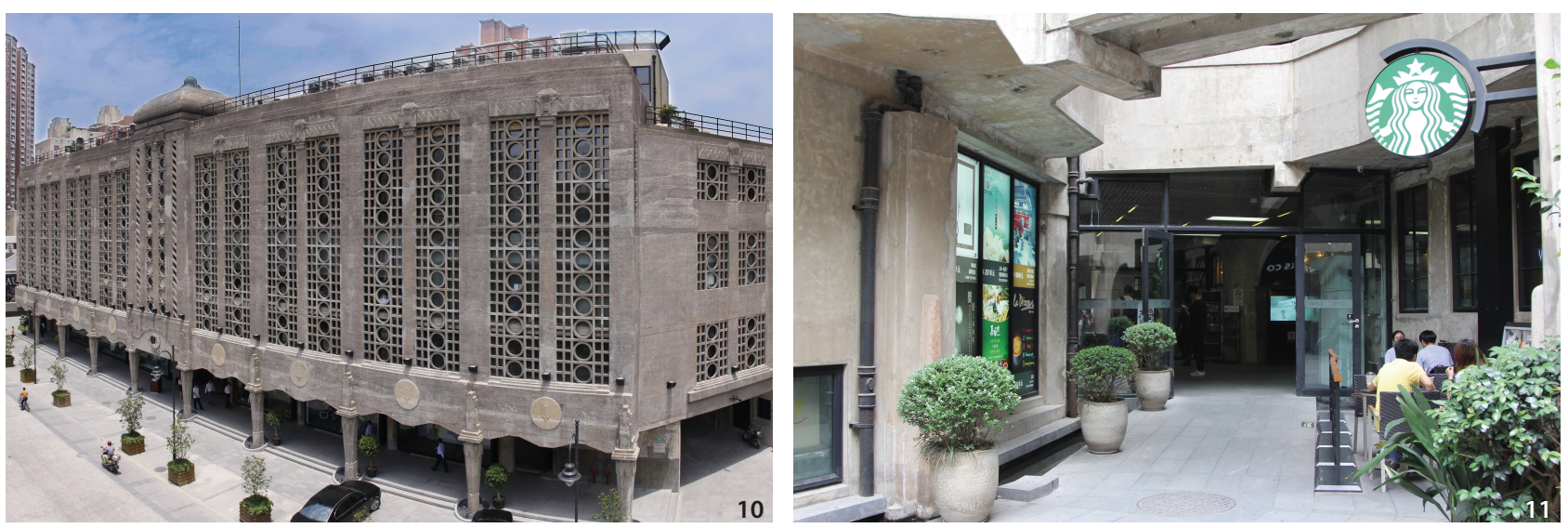

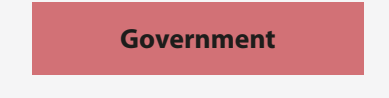

Accorded heritage status; provided policy support for operation and development.

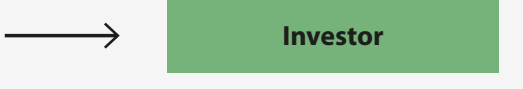

A government-owned corporation (SCIC) invested/financed the project, and operates management service.

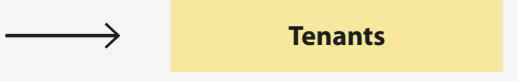

Design-related professionals and retailers leased office space or retail units from SCIC. 


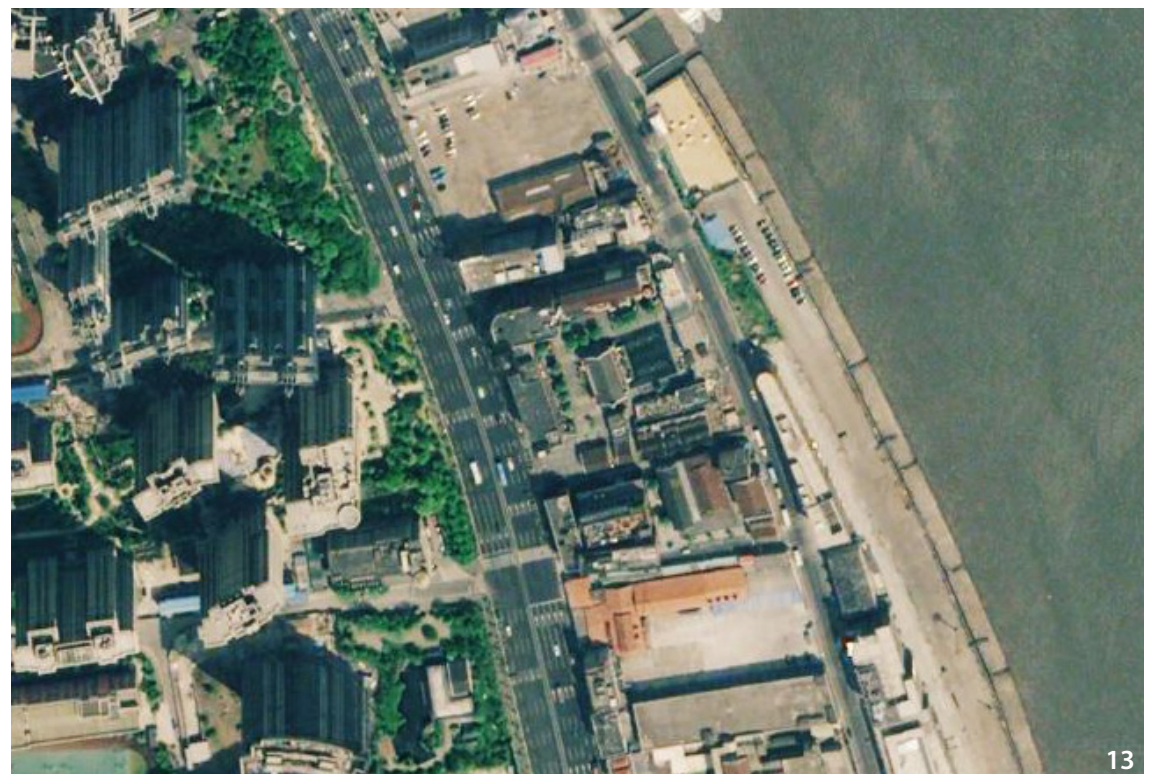

Figure 13 Satellite image of the Cool Docks (Source: Baidu Map). retired municipal government engineer), Xue Shunsheng, who began campaigning for the protection of the building (Shanghai Creative Industry Investment Co. Ltd 2007; Wang and Pendlebury 2015). Benefiting from the growing awareness of the need to protect historic buildings in Shanghai, the slaughterhouse was listed as Heritage Architecture by the municipal government in 2005 .

Coincidently, in the same year, the SCIC was established to provide financial and technical support to startup companies with the aim of boosting the creative economy in the city. Unconventionally perhaps, this municipal government agency was given the mission to take on regeneration work by converting obsolete state-own industrial properties into workplaces for creative and knowledge workers (Zheng 2010). Thus, the SCII was formed, with SCIC as one of the three shareholders, to embark on a new venture to convert dilapidated manufacturing industrial sites into fashionable workplaces for creative industries (Shanghai Creative Industry Investment Co. Ltd 2007). With its exceptional architectural and aesthetic values, the former SMC Abattoir was purposely chosen to be the flagship regeneration project of SCII, known as 1933 Old Millfun, to demonstrate the enormous economic potential of industrial heritage. When the building was designated as a municipal CIC in 2006, conservation work was also initiated and carried out in a meticulous manner because of its heritage status. In contrast to M50, a wide range of contemporary design features and elements were introduced to this heritage building for the express purpose of attracting fashionable design-related tenants and highend retailers upon completion. The building was renamed 1933 Shanghai in 2007 after SCIC leased the property to a private management company and was awarded the title of an 'Outstanding CIC' by the local government in 2008 (Wang 2013)(Figure 9-11).

The regeneration process of 1933 Shanghai was led by the local government with investments from the municipally owned SCII; it also benefited from various governmental support throughout the process. Thus, this represents a clear top-down approach toward regeneration. After SCII completed the conservation and renovation of the SMC Abattoir, they leased the premises to a private property management company for day-to-day management and operation, Shanghai Zhongheng Enterprise Management Consulting Co. Ltd (Zhongheng, hereinafter). Since then, the business operation of this CIC has been run by the private corporation with a more commercial approach and a strong focus on generating revenue: 'We are an independent business corporation, not led by SCIC', said one of the managers of Zhongheng, although 'SCIC provided suggestions and "guidelines" for regenerating this site. The manager explained that, the key rationale for this project was to 'combine cultures with commercial benefits', and that 'a profit-generating process' is equally important and 'through the management of Zhongheng, the embedded economic values of this state-owned property are enhanced' (Figure 12).

\section{Cool Docks}

To the east of the Old City and on the west bank of Huangpu River, the Cool Docks is located at the historical shipping dock, Shiliupu (Figure 13). The area was once a key trading centre in Shanghai, and has been witness 


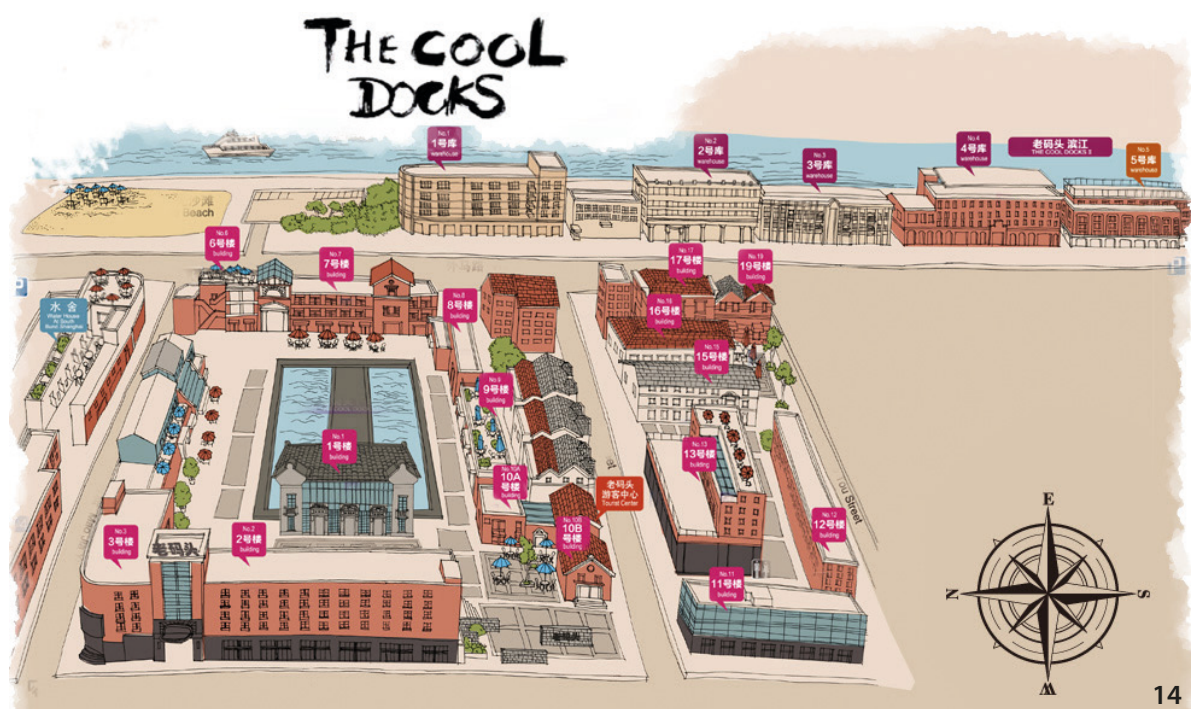

Figure 14 Illustration of the Cool Docks (Source: The Cool Docks, en.thecooldocks.com).

Figure 15 The 1930s warehouse buildings along the Huangpu River (Source: Yi-Wen Wang).

Figure 16 The reconstructed Building No.1 with an appearance similar to Shikumen houses (Source: Yi-Wen Wang).

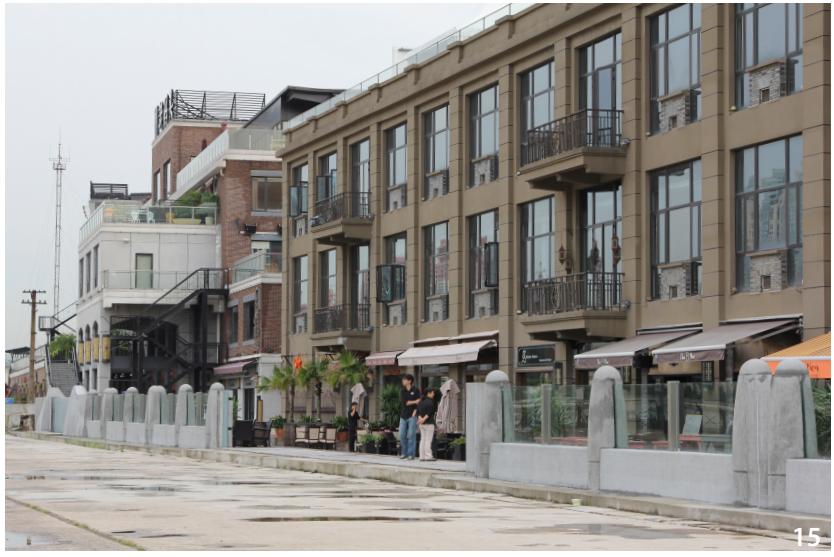

to the city's economic transformation for more than 100 years ( $\mathrm{Lu}$ et al. 2012). Buildings in the area also represent multiple layers of history, which include warehouses built between 1900s and 1930s in both vernacular and modernist styles, and traditional dwellings known as shikumen (a type of building) and lilong (neighbourhood layout), together with several large factories and office buildings built in the 1980s and 1990s.

Following the rehabilitation project of Suzhou Creek in the late 1990s, the municipal government began to regenerate the brownfield sites along the Huangpu River in 2002 after the shipping and shipbuilding industries had been relocated to the coastal areas of the city ( $\mathrm{Gu} 2013)$. This river and waterfront regeneration project started in the northern commercial section, that is, the Bund and Pudong, and was then extended to the southern part of the former industrial premises. The regenerated river embankment is lined with a promenade deck that opens up the previously inaccessible industrial waterfront to the general public, and is accompanied with various amenities, services and activities. This government initiative

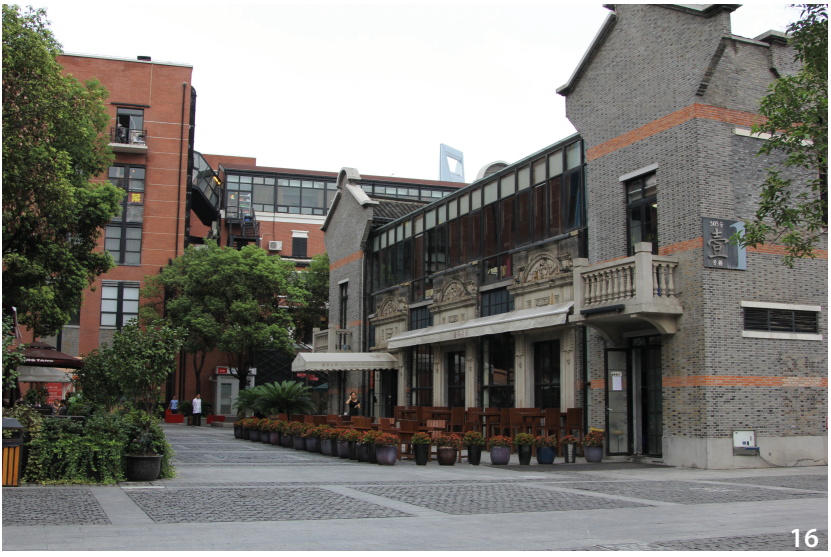

to clean up the river and improve public spaces on the Huangpu riverside drew the public's attention, especially property developers, to the brownfield sites of Shiliupu (Liu and Li 2011).

Similar to M50 on the Suzhou Creek, the Cool Docks CIC significantly benefited from the rehabilitation of Huangpu River. In contrast to M50, however, the conversion of factories and warehouses in Shiliupu into a site for creative industries was initiated and led by a property development company, Hongji Property Co. Ltd (hereinafter Hongji), instead of artists. This regeneration process also displays a somewhat 'bottom-up' approach, but more specifically, it is a market-oriented strategy for industrial heritage valorisation.

Construction work began in 2007, and Hongji claimed that the design rationale for this project was to capitalise on traditional Shanghai cultures by recalling the history of the place. The focal point of this area, Building No. 1, was reconstructed using reclaimed materials from shikumen houses that were demolished on site. The stone gates and gabled walls from shikumen buildings were reused to 


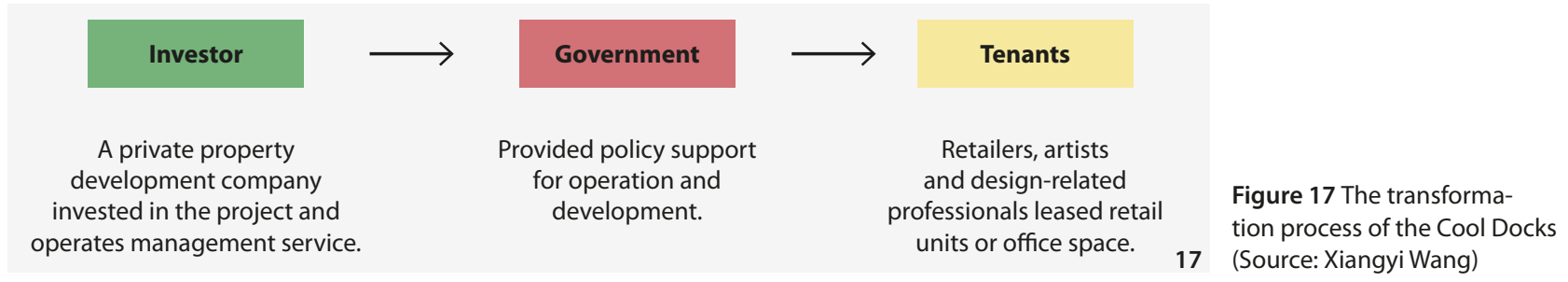

resonate with people's impressions about the characteristics of Shanghai architecture (Zhu 2013). Essentially, it was a complete reconstruction or interpretation similar to the 'regeneration' approaches adopted in Xintiandi in Shanghai. Meanwhile, warehouses along the Huangpu River were conserved and refurbished to attract those retailers and companies seeking a riverside view (Figure 14-16).

In term of boosting creative industries, fashion design was touted as a key industry to be housed in these premises. Sited on the west end of a rectangular water feature, Building No. 1 was designed to include an indoor stage extending to outdoors and over a shallow pool, as if it was a catwalk rising up from the water. Attracted by the riverside location and historical industrial and residential buildings, a few high-end restaurants, bars, boutique hotels, designer stores soon opened. As a result, this mixture of creativity with leisure and luxury saw the Cool Docks an area for leisure or sightseeing instead of creative workers (Lu et al. 2012).

Despite the perceived exclusiveness of the project, the Huangpu District Government designated the Cool Docks a CIC upon the completion of regeneration work in 2008 and placed it in the 'Top 10 CIC' in the same year (Wang 2013). The manager of Hongji proudly explained that 'We have been doing something way ahead of the local government. This successful case has shown our superior skills in regeneration projects as well as our keen interests and responsibility for developing sites [with cultural heritage assets] like this'. As a result of this project, 'the District Government is now planning to set up a creative cluster [for the South Bund regeneration project] alongside Huangpu River', which later became the venue of the Expo 2010 Shanghai (Figure 17).

\section{Discussion}

A comparison of the development timeline of the three cases enables us to gain a better understanding of how the public and private sector entered the arena of industrial heritage valorisation and the roles they have played (Table 2). From the three case studies, it is discernible that the local government utilised three regulatory instruments: the designation as a CIC, the listing of a building as Heritage Architecture, and accreditation for CIC operation. None of these three instruments, however, have proven effective or critical to the transformation of the three industrial sites. The heritage status, while never conferred to M50 and the Cool Docks, cannot be directly attributed to the conversion of 1933 Shanghai either. Apart from M50, a spontaneously formed creative cluster, the CIC status accorded by the government often came after the conversion work, as did the accreditation for CIC operation. The trajectory of the three selected cases, to some extent, has shown that the municipal government gradually adapted its role, starting as a bystander, becoming an active promoter and then a passive facilitator. On the other hand, the interests of the private sector in developing CICs as well as reusing industrial heritage structures have markedly increased. It can be argued the growth of privatesector interests in regenerating historical structures has derived from the general public's increasing appreciation for historical structures. As a result, more and more developers have begun to embark on ventures to convert the cultural value of heritage architecture into an economic one. Likewise, while greater numbers of former industrial buildings and sites have been saved and repurposed, such profit-driven and market-orientated regeneration has also resulted in more drastic physical alterations to existing industrial sutures, and this has arguably diminished the authenticity and integrity of the relics of Shanghai's industrial past.

This shift from top-down public campaigns to bottomup private interests in regenerating industrial sites has shown the prominence of the private sector in enabling Shanghai to restructure its industrial sectors toward the creative economy. However, such market forces should be integrated into urban regeneration processes with caution and carefully regulated. The private sector, motivated by profits, should not be the sole enabler for the transformation of industrial sites or, more broadly, urban generation. Taking Cool Docks as an example, the enhanced appreciation and heritage value of industrial buildings has been accompanied by the soaring values of nearby properties. 
Table 2 The development timeline of the three cases (Source: adapted from Wang 2013).

\begin{tabular}{|c|c|c|c|}
\hline & M50 & 1933 Shanghai & The Cool Dock \\
\hline 1900s & & & Warehouses constructed \\
\hline $1910 s$ & & & \\
\hline $1920 \mathrm{~s}$ & & & \\
\hline 1930s & Factories built & Slaughtershouse constructed & \\
\hline$\cdots$ & $\begin{array}{l}\text { Suzhou Creek Rehabilitation } \\
\text { Project (1996) }\end{array}$ & & \\
\hline 1999 & Factory ceased operation & & \\
\hline 2000 & $\begin{array}{l}\text { Artists set up studios on the } \\
\text { industrial estate, No. } 50 \text { Mo- } \\
\text { ganshan Road. }\end{array}$ & & \\
\hline \multicolumn{4}{|l|}{2001} \\
\hline 2002 & $\begin{array}{l}\text { The industrial premises was } \\
\text { listed as 'Chunming Urban } \\
\text { Industry Park' by local govt. }\end{array}$ & $\begin{array}{l}\text { Slaughter was shut } \\
\text { down after the last company } \\
\text { moved out. }\end{array}$ & \\
\hline \multicolumn{4}{|l|}{2003} \\
\hline 2004 & $\begin{array}{l}\text { Renamed as 'Chunming Art } \\
\text { Park' by the original factory } \\
\text { owner }\end{array}$ & & \\
\hline 2005 & $\begin{array}{l}\text { Designated as 'M50 CIC' by } \\
\text { local govt. }\end{array}$ & $\begin{array}{l}\text { Listed on the Forth Bath of } \\
\text { Heritage Architecture by mu- } \\
\text { nicipal govt. }\end{array}$ & \\
\hline \multirow[t]{2}{*}{2006} & \multirow{2}{*}{$\begin{array}{l}\text { The owner completed reha- } \\
\text { bilitation work }\end{array}$} & $\begin{array}{l}\text { Leased to SCIC and started } \\
\text { conservation work }\end{array}$ & \\
\hline & & $\begin{array}{l}\text { Designated as 'CIC' by local } \\
\text { govt. }\end{array}$ & \\
\hline 2007 & $\begin{array}{l}\text { Awarded as 'Outstanding } \\
\text { CIC' by local govt. }\end{array}$ & $\begin{array}{l}\text { Renamed as } 1933 \text { Shanghai } \\
\text { and open to the public }\end{array}$ & $\begin{array}{l}\text { Shanghai Hongji Property } \\
\text { Company initiated the re- } \\
\text { generation/development }\end{array}$ \\
\hline 2008 & $\begin{array}{l}\text { Renamed as 'M50' and brand } \\
\text { building began }\end{array}$ & $\begin{array}{l}\text { Awarded as 'Outstanding } \\
\text { CIC' by local govt. }\end{array}$ & $\begin{array}{l}\text { Designated as 'The Cool } \\
\text { Docks CIC' by local govt. }\end{array}$ \\
\hline \multirow[b]{2}{*}{2009} & & \multirow[b]{2}{*}{$\begin{array}{l}\text { Hosted 'Shanghai Design' } \\
\text { opening ceremony }\end{array}$} & High-end retailers moved in \\
\hline & & & $\begin{array}{l}\text { Awarded as one of the 'Top } \\
10 \text { CIC' in } 2008 \text { and } 2009 \text { by } \\
\text { local govt. }\end{array}$ \\
\hline 2010 & $\begin{array}{l}\text { Awarded as 'Supreme Exam- } \\
\text { ple of CIC' by local govt. }\end{array}$ & & \\
\hline
\end{tabular}

Building constructed

Conservation project

Tenants' residence

Heritage designation

$\mathrm{CIC}$ designation

Recognition from municipal/local govt.
As the project targeted high-income groups, gentrification and subsequent socio-economic impacts are foreseeable and inevitable. Likewise, it can be argued that the revitalisation of this brownfield site and its warehouse buildings was achieved at the cost of the substantial demolition of shikumen buildings. From the interviews, it appears that Cool Docks was never geared toward the development of creative industries but instead the generation of 'creative revenue. Admittedly, the private sector (and especially property developers) has played a critical role in perceiving and responding to the need of potential buyers and retailers, and it has helped revitalise many abandoned areas in the city. Thus, it is important to assess whether the benefits of private investment in regeneration outweigh the risks of losing the common goods as well as a city's historical urban fabric.

Conversely, the investigation of these three case studies has revealed that the local government started as a mere bystander in promoting creative industries at M50; it then transitioned to become a proactive policy implementer for the flagship 1933 Shanghai, and later a passive facilitator in the case of the Cool Docks. In the early 1990s, following the exodus of manufacturing establishments, neither the central nor local governments viewed the deserted 
state-owned industrial properties as 'cultural assets' to be reused or preserved. In the mid-2000s, the municipal government's introduction of the CIC policy as a planning instrument to transform former industrial premises into loci of innovation and creativity was inspired by the spontaneous clustering of artists and freelance workers gathering in disused factories, like those along Suzhou Creek (i.e., M50). The establishment of SCIC to promote and regulate creative industries was a deliberate attempt by the municipal government to prompt economic growth in the 'creative' sector; even so, the municipal government has had a greater impact as an investor valorising disused industrial sites than as a CIC policy implementer (Wang 2009).

While SCIC were given the challenging task of converting a myriad of state-own industrial properties into creative workplaces, its primary mission was to generate economic benefits rather than safeguarding industrial heritage. Interviews with SCIC officials also confirm that conserving industrial structures of special architectural or historical interest was never a strategic priority of the organisation. Our on-site observations also found that 60 percent of the floor use in 1933 Shanghai is designated to commercial operations, which is the same as the purely private-led and very much commercialised Cool Docks. SCII was a unique investment entity that did not need to register a trademark with the municipal government but received considerable financial and government support from it. As one of the cofounders of SCII, SCIC engaged and invested in the trade that it governed and regulated (Shanghai Creative Industry Investment Co. Ltd no date). After succeeding in making 1933 Shanghai a flagship CIC, SCII went on to regenerate many other state-owned industrial sites and SCIC increasingly embraced its role as an investor rather than a regulator (Zheng 2010).

The relationship between the public and private sector in urban regeneration is undeniably intricate. While the private sector is able to recognise market demand, it is possibly ready to lower its expectations regarding incubating creativity, and it is always ready to compromise during the profit-making process. In the absence of a strict and well-defined regulation for industrial heritage regeneration, the integrity and authenticity of Shanghai's industrial heritage has been prone to compromise. Almost all the CICs located on former industrial sites were developed with middle-high socio-economic groups as target customers, retailers, office leaseholders or consumers. Gentrification and over-commercialisation has become a recurrent practice in many CICs that possess some degree of post-industrial architecture characteristics. The recent delisting of some unqualified CICs (Luan, Wang, and An 2013), to some extent, reflects the gravity of this problem and the intention of local authorities to address them. The gradual withdrawal of the government in developing CICs suggest that local government is inclined to give more room to the private sector to 'do the things they are good at'. This situation, nonetheless, should not be simplified or concluded as the ending of government intervention.

\section{Conclusions}

Drawing on these three case studies, this research has revealed that the roles and positions of the three major stakeholder groups involved in the creation of CICs have changed gradually throughout the process. Whereas the private sector and the general public have developed increasing interests in the embedded economic and cultural values of former industrial structures, local authorities have consciously reduced their presence and influence in valorising industrial heritage. Intrinsic to Shanghai's reindustrialisation in the $21^{\text {st }}$ century is the rising public awareness of cultural heritage and the increasing interest in the creative economy.

Admittedly, these three cases only provide a snapshot and are by no means representative of the overall trend of Shanghai's industrial heritage valorisation and creative industry proliferation in the first decade of the $21^{\text {st }}$ century. Likewise, this research has placed much of its focus and emphasis on industrial heritage regeneration and its correlation with the development of CICs. Whereas CICs based on industrial sites have been the most common regeneration model in boosting Shanghai's creative economy, their effectiveness in attracting knowledge workers and investment may remain limited or, at least, questionable. Thus, the rise of the creative class and milieu cannot rely solely on the CICs scattered around the city-one must also look to the cultures of creativity and innovation prevailing throughout the city. On this account, visionary leadership of the local government is indeed indispensable (Florida 2005; Landry 2008).

Moving into the second decade of the $21^{\text {st }}$ century, Shanghai adopted a different, more rigorous approach toward the development of the creative economy. Several initiatives undertaken or launched in 2010 signify the municipal government's shift in governance and management. The holding of Expo 2010 Shanghai provided the city with an unprecedented opportunity to give thought to its previous approach to industrial heritage regeneration as well as creative economy development. Furthermore, the Shanghai Cultural and Creative Industry Promotion 
Leading Group was established, with its primary mission being to analyse, formulate policies and coordinate the development of cultural and creative industries. That group serves as an advisor to district governments to improve, oversee and manage industrial heritage conservation work while promoting creative industries. In the same year, Shanghai successfully joined the global 'Creative City Network' and was awarded the title of 'Capital of Design' by UNESCO. Subsequently, UNESCO's 'Creative City' (Shanghai) Promotion Office was established, responsible for promoting innovation and creativity in the city. This is a new approach, asking the public sector to prompt creative industries and fuel urban regeneration. It no longer plays the role of investor, but instead focuses on the creation of a creative city, including revitalising former industrial sites. Through the efforts of the leading group and the promotion office, the local authority has changed its approaches toward former industrial sites from industry upgrades to 'making the city better'.

This phenomenon reflects the changes in attitude and the shift of focus of the local government toward valueoriented urban regeneration, often termed 'organic urban renewal' (Tang 2015). Previously, the conversion of industrial sites placed much of its emphasis on the upgrading of secondary and tertiary industries and their contribution to the city's economic growth. Nowadays, the government directives have increasingly mandated the provision of employment opportunities for a wider range of socio-economic groups. Apart from high-paid skilled knowledge workers, the creation of low-end jobs and revenue for the public sector are now a fundamental requirement for all regeneration projects. Although property developers still play a key role and problems of gentrification persist, the development of CICs has begun to take on more social responsibilities by creating more low-end jobs and contributing to public revenue for the city.

Furthermore, the Shanghai municipal government has endeavoured to establish a new urban regeneration regime that places greater attention on vulnerable groups, balances the development of different city areas and promotes social values. In 2017 the municipal government published 'Several Opinions on Deepening Organic Urban Renewal and Promoting Historical Scenery Protection' (Shanghai Municipal Govertment 2017), and the 'Life Cycle Management for Land' has become a new priority for the government in industrial heritage regeneration and conservation. Under this new regulation, public interest and heritage authenticity is highly valued. Urban entrepreneurism has been stimulated and the private sector is now encouraged to come part of city branding activities. The Xuhui Riverbank Area is an exemplar of this new change. The local authority encompasses industrial heritage reuse, public space improvement and function expansion within a single regeneration programme. The public-private partnership of this regeneration project is set to build an 'Industrial Heritage Gallery', so as to open a new chapter in the regeneration of Xuhui District. Looking to the future, with more sophisticated policies in place, the economic contributions of cultural and creative industries would not be the only consideration for private sectors. Thus, a win-win-win solution that benefits city reindustrialisation, private interest and public good will be gradually realised.

\section{Acknowledgment}

The authors would like to thank the anonymous reviewer and Dr. Plácido González Martínez, the executive editor of Built Heritage, for their helpful comments on the early version of this article.

\section{References}

Denison, Edward, and Guangyu Ren. 2006. Building Shanghai: The Story of China's Gateway. Chichester: Wiley Academy.

Florida, Richard L. 2005. Cities and the Creative Class. New York: Routledge.

Friedmann, John. 2005. China's Urban Transition. Minneapolis: University of Minnesota Press.

González Martínez, Plácido. 2017. "Urban Authenticity at Stake: A New Framework for Its Definition from the Perspective of Heritage at the Shanghai Music Valley." Cities 70: 55-64.

$\mathrm{Gu}$, Kun. 2013. "Pujiang liang'an zhongdian diqu gongye yichan baohu yanjiu." [The Conservation of Industrial Heritage of Vital Areas Along Huangpu River] Urban Planning Forum 2013 (8): 141-153.

$\mathrm{Gu}$, Xin. 2012. "The Art of Re-Industrialisation in Shanghai." Culture Unbound: Journal of Current Cultural Research 4 (3): 193-211.

He, Jinliao. 2014. Creative Industry Districts: An Analysis of Dynamics, Networks and Implications on Creative Clusters in Shanghai. Cham, Switzerland: Springer International Publishing.

He, Wei, and Xiaoming Zhu. 2012. "Shanghai gongbuju zaishengchang jianzhu dang'an yanjiu." [A Research on the Architectural Archives of the Shanghai Municipal Council Abattoir] Time+Architecture 2012 (3): 105-113. 
He, Wei. 2011. "Shanghai gongbuju zaishengchang jianzhu dang'an yanjiu." [Research on Architecture Archives of the Slaughter House of Shanghai Municipal Council] Master Diss., Tongji University.

Ju, Ye-Xin, Hong-Yuan Mei, and Teng Fei. 2010. "Cong jiuchangfang dao bowuguan-gongye yichan baohu yu zaisheng de xin tujing." [From Old Factory to Museum: New Way of Industry Heritage Protection and Regeneration] Building Science 26 (6):14-17.

Kong, Lily, and Justin O'Connor, eds. 2009. Creative Economies, Creative Cities: Asian-European Perspectives The Geojournal Library. Dordrecht Springer.

Landry, Charles. 2008. The Creative City: A Toolkit for Urban Innovators. 2nd ed. London: Earthscan.

Liu, Cheng, and Zhen Li. 2011. "Qianlun Shanghai gongye yichan zaisheng moshi-shibo beijing xia gongye yichan de zuotian jintian he mingtian." [The Reuse Pattern of Shanghai Industrial Heritage: Yesterday,Today and Tomorrow of Industrial Heritage over Expo 2010] Huazhong Architecture 2011 (3):177-182.

Lu, Shao-Ming, Jia-Hui Diao, Hao-Lin Zhao, Zhao Li, Li Ye, and Xian Wang. 2012. "Gangkou chengshi de jiti jiyi 'matou yichan'-yi Shanghai weili." [Study on Collective Memories in Port Cities: A Case Study of Shanghai] Modern Urban Research 2012 (10): 39-49.

Luan, Feng, Huai Wang, and Yue An. 2013. "Shanghai shishu chuangyi chanye yuanqu de fazhan licheng yu zongti kongjian fenbu tezheng." [The Development of Creative Industrial Parks in Shanghai and Their Spatial Features] Urban Planning Forum 2013 (2): 70-78.

Ma, Yun-Xia. 2009. "Dui Shanghai jiu gongye yichan baohuqu-Shanghai chuangyi chanye yuanqu xianzhuang de fansi." [Consideration on the Preservation and Rehabilitation of Shanghai Industrial Heritage] Industrial Construction 39 (12): 36-38.

O'Connor, Justin, and Xin Gu. 2012. "Creative Industry Clusters in Shanghai: A Success Story?” International Journal of Cultural Policy 20 (1): 1-20.

O’Connor, Justin. 2009. "Shanghai Moderne: Creative Economy in a Creative City?" In Creative Economies, Creative Cities: Asian-European Perspectives, edited by Lily Kong and Justin O'Connor, 175-193. Dordrecht: Springer.

Pendlebury, John, Yi-Wen Wang, and Andrew Law. 2018. "Re-Using 'Uncomfortable Heritage': The Case of the 1933 Building, Shanghai." International Journal of Heritage Studies 24 (3): 211-229.

Ruan, Yisan, and Song Zhang. 2004. "Chanye yichan baohu tuidong dushi wenhua chanye fazhan-Shanghai wenhua chanyequ mianlin de jiyu." [The Promotion of Industrial Heritage Conservation on Cultural Business: The Difficulties and Opportunities for Cultural Industry Clusters Development in Shanghai] Urban Planning Forum 2004 (4): 53-57.

Shanghai Creative Industry Investment Co. Ltd. 2007. 1933 Old Millfun. Shanghai: Lianghong Print.

Shanghai Municipal Administration of Culture, Radio Broadcasting, Film and Television. 2012. "Dui Shanghai wenhua chuangyi chanye yuanqu fazhan moshi de lujing de diaoyan yu sikao." [Analysis of the Development Pattern of Cultural and Creative Industry Clusters in Shanghai] Accessed 28 January 2014. http://wgj. sh.gov.cn/wgj/node743/node763/node1350/u1a78893. html

Shanghai Municipal Govertment. 2017. "Guanyu shenhua chengshi youji gengxin cujin lishi fengmao baohu gongzuo de ruogan yijian." [Several Opinions on Deepening Organic Urban Renewal and Promoting Historical Scenery Protection] Shanghai: Shanghai Municipal Govertment.

Tang, Zilai. 2015. "Chengshi gengxin de jiazhi quxiang." [The Value Orientation in Urban Regeneration] In Chengshi youji gengxin Shanghai zai xingdong [Organic Urban Renewal: Shanghai in Action], edited by Shanghai Planning and Land Resource Administration Bureau and Shanghai Urban Planning and Design Research Institute, 260-263. Shanghai: SUSAS.

Tung, Chien-Tzu. 2009. "Shanghai wenhua chuangyi chanye kongjian fazhan jizhi yanjiu: tianzifang, M50 yu Laochangfang." [The Spatial Mechanisms of Cultural Creative Industrial Development in Shanghai: Case Study by Tianzifang Community, M50 and Old Millfun 1933] Master diss., Ming Chuan University.

Wang, Jun. 2009. “'Art in Capital': Shaping Distinctiveness in a Culture-Led Urban Regeneration Project in Red Town, Shanghai.” Cities 26 (6): 318-330.

Wang, Xiangyi. 2013. "From Industrial Heritage to Creative Industry: A Case Study of Shanghai." Bachelor diss., Xi'an Jiaotong-Liverpool University.

Wang, Yi-Wen, and John Pendlebury. 2015. “1933 Building, Shanghai: A Machine for Killing, a Machine for Consumption.” International Conference - Heritage of Death: Landscapes, Sentiment and Practice, Stockholm, 10-11 September 2015.

Wang, Yi-Wen, and John Pendlebury. 2016. "The Modern Abattoir as a Machine for Killing: The Municipal Abattoir of the Shanghai International Settlement, 1933." Architectural Research Quarterly 20 (2): 131-144. 
Wu, Fulong. 2000. "The Global and Local Dimensions of Place-Making: Remaking Shanghai as a World City." Urban Studies 37 (8): 1359-1377.

Zhang, Song, and Peng Chen. 2010. "Shanghai gongye jianzhu yichan baohu yu chuanyi yuanqu dazhan-jiyu hongkouqu de diaocha fenxi yiqi sikao." [Conservation of Shanghai Industrial Building Heritage and Development of Creative Industry Park: Based on Investigation, Analysis and Consideration on Hongkou District] Architectural Journal 2010 (12): 12-16.

Zhang, Song. 2007. "Conservation and Adaptive Reuse of Industrial Heritage in Shanghai." Frontiers of Architecture and Civil Engineering in China 1 (4): 481-490.

Zhao, Chongxin. 2007. "Mo chulai de shuini shijie: 1933 laochangfang sheji zhaji." [The World of Cement by Grinding Out] Architecture and Culture 42 (08): 33-37.

Zheng, Jane. 2010. "The 'Entrepreneurial State' in 'Creative Industry Cluster' Development." Journal of Urban Affairs 32 (2): 143-170.

Zheng, Jane. 2011. "Creative Industry Clusters' and the 'Entrepreneurial City' of Shanghai." Urban Studies 48 (16): 3561-3582.

Zhong, Sheng. 2009. "From Fabrics to Fine Arts: Urban Restructuring and the Formation of an Art District in Shanghai." Critical Planning (16): 118-137.

Zhong, Sheng. 2010. "Industrial Restructuring and the Formation of Creative Industry Clusters: The Case of Shanghai's Inner City." PhD diss., University of British Columbia.

Zhu, Huang. 2013. "Lishi jiu jianzhu gaizao guihua sheji yanjiu-yi Shanghai Waimalu laomatou guihua gaizao xiangmu sheji weili." [Study on Planning and Design of Historic Buildings Regeneration-a Case of the Cool Docks] Construction and Equipment 2013 (1). 